\title{
Q Utilização de formas alternativas de desbaste químico no superbrotamento de bananeira
}

Hellenn Thallyta Alves e Mendes ${ }^{1}$

Danilo Nogueira dos Anjos²

Abel Rebouças São José3

Gildardo Vazquez Arciga ${ }^{4}$

\section{Resumo}

A banana "Maçã" apresenta alta suscetibilidade à fusariose. Assim, o presente trabalho teve por objetivo avaliar diferentes formas de desbaste químico com glifosato, em brotos de bananeira "Maçã", visando à redução da transmissão do Fusarium oxyporum, agente causal do Mal-do-panamá. 0 experimento foi instalado com cinco tratamentos no delineamento experimental inteiramente casualizado, no qual cada parcela foi constituída de quatro plantas de banana "Maçã". Os tratamentos testados correspondem a cinco formas de aplicação do glifosato herbicida nos brotos (vela) de cada planta: T1- testemunha, T2- palito de picolé, T3- palito roliço de madeira para os dentes, T4- palito roliço de madeira para churrasco, T5- seringa. A avaliação visual do efeito de toxicidade nos brotos foi realizada aos 15, 30 e 60 dias após a aplicação dos tratamentos. Foram atribuídas notas de um a nove, de acordo com a severidade do dano nos brotos. O desbaste químico por meio da injeção do herbicida pela seringa foi a mais eficiente forma de aplicação em todas as épcaocas, levando à morte cem por cento dos brotos, a partir dos 15 dias após a aplicação do produto, o que pode ser uma excelente alternativa para o desbaste, reduzindo assim a transmissão do Fusarium oxysporum.

Palavras-chave: Mal-do-panamá. Glifosato. Musa spp.

\section{Introdução}

A banana é a fruta mais consumida e a segunda mais produzida no Brasil, constituindo uma das atividades agrícolas de maior importância econômica nesse país. Segundo dados da FAO (2014), o Brasil é o quinto maior produtor mundial de banana, ficando abaixo da Índia, China, Filipinas e Equador, com uma área plantada de 481,116 mil hectares e produção de 6,9 bilhões de toneladas. O estado de São Paulo é o maior produtor nacional, seguido pelos estados da Bahia, Santa Catarina e Minas Gerais. A região Nordeste destaca-se como maior produtora de banana do país, com produção de 2,4 bilhões de toneladas, seguida pelas regiões Sudeste e Sul, com 2,28 e 1,07 bilhões de toneladas de frutos produzidos, respectivamente (IBGE, 2014).

Um dos principais problemas da bananicultura brasileira é o Mal-do-panamá ou murcha de

1 Universidade Estadual do Sudoeste da Bahia, pesquisadora de doutorado. Vitória da Conquista. Bahia. Brasil. helen.talyta@hotmail. com (77) 9112-0143. Rua Antônio Dantas, 1141, Santa Cecília, Vitória da Conquista, Bahia CEP 45005-374.

2 Universidade Estadual do Sudoeste da Bahia, pesquisador de mestrado. Vitória da Conquista. Bahia. Brasil. danylodosanjos1@ hotmail.com (77) 8825-0853. Rua Antônio Dantas, 1141, Santa Cecília, Vitória da Conquista, Bahia CEP 45005-374.

3 Universidade Estadual do Sudoeste da Bahia, professor pesquisador. Vitória da Conquista. Bahia. Brasil. abeljose3@gmail.com (77) 8823-5117. Estrada do Bem querer, Km 4, caixa postal 95, Vitória da Conquista, Bahia CEP 45083-900.

$4 \quad$ Universidad Autónoma Chapingo, pesquisador de graduação. Vitória da Conquista. Bahia. Brasil. gilo_715@hotmail.com (77) 9168-4995. Rua Antônio Dantas, 1141, Santa Cecília, Vitória da Conquista, Bahia CEP 45005-374. 
fusário - que tem como agente etiológico o fungo de solo Fusarium oxysporum f. sp. cubense (E.F. Smith) Snyder \& Hansen. Esse fungo infecta diversas variedades de bananeira e encontra-se amplamente difundido no Brasil, causando prejuízos aos produtores (BORGES et al., 2007).

De acordo com Stover e Waite (1960), são conhecidas quatro raças de Fusarium oxysporum f. sp. cubense, e cada uma delas apresenta especificidade distinta, de acordo com as cultivares de bananeira. As raças 1, 2 e 4 atacam principalmente as cultivares do subgrupo Gros Michel, Cavendish $(A A A)$, Prata $(A A B)$ e Bluggoe (ABB), e a raça 3 infecta especificamente espécies de helicônia. Dessas, apenas a raça 4 ainda não foi constatada no Brasil (CORDEIRO e KIMATI, 1997). A variedade Maçã $(A A B)$ é suscetível à fusariose e o seu plantio está sendo priorizado em locais isolados e em solos não cultivados com a banana (BORGES et al., 2007). Em razão da inviabilização desse cultivo em algumas regiões do país, o preço da banana-maçã vem sofrendo constante aumento (LEONEL; DAMATTO JUNIOR, 2007).

O Fusarium oxysporum pode ser disseminado pela água, pelo solo, pelos implementos agrícolas e máquinas (PLOETZ, 2006) ou ainda por meio de ferramentas contaminadas, utilizadas principalmente no desbaste dos brotos. Essa ação pode causar ferimentos que servem como porta de entrada para o agente causal do Mal-do-panamá (LEONEL e DAMATTO JUNIOR, 2007). Com o objetivo de diminuir a disseminação da doença nas lavouras de banana "Maçã", os produtores têm conduzido a cultura com cinco a seis touceiras, o que superestima a produção dessa variedade, pois a recomendação para a sua condução é de três touceiras (EMBRAPA, 2009). O manejo com o número de plantas acima da recomendada exige quantidades maiores de nutrientes e maior demanda de água entre outros fatores de produção. Torna-se necessário, portanto, o uso de práticas alternativas para o desbaste dos brotos.

$\mathrm{O}$ herbicida utilizado neste ensaio para o desbaste dos brotos é à base de glifosato [N-(fosfonometil) glicina], pós-emergente, sistêmico e não seletivo (COX, 2000). O glifosato é absorvido e translocado nas plantas, promovendo eficiente controle das plantas indesejadas nos estádios em que a competição seria extremamente negativa para a cultura (ANDRADE e ROSOLEM, 2011). Segundo a ANVISA (BRASIL, 2014), esse herbicida está inserido na classificação toxicológica III- mediamente tóxico, e na classificaçao do potencial de periculosidade ambiental Categoria III - produto perigoso ao ambiente (BRASIL, 2014).

Herbicidas à base de glifosato têm sido utilizadas para destruir bananeiras novas ou doentes como uma forma de controle à proliferação de doenças causadas por fungos, bactérias ou vírus (MARTINEZ et al., 1988; OKURUT et al., 2006; BLOMME et al., 2008).

O único controle efetivo que ainda existe para o Mal-do-panamá é o plantio de clones e cultivares tolerantes a essa doença (CORDEIRO e KIMATI, 1997). Porém, uma alternativa que pode contribuir para o controle integrado do Mal-do-panamá na bananeira é a eliminação de brotos novos, por meio da erradicação química por intrusão físico/mecânica. Essa prática vem sendo estudada na África, na cultura da banana, para o controle de brotos e para evitar a disseminação de Xanthomonas campestris (LINDSAY et al., 2003; OKURUT et al., 2006; BLOMME et al, 2008; JEROME et al, 2014).

Diante do exposto, objetivou-se com o presente trabalho avaliar diferentes formas de desbaste químico com glifosato, em brotos de bananeira "Maçã", visando à redução da transmissão do Fusarium oxyporum, agente causal do Mal-do-panamá. 


\section{Material e Métodos}

O experimento foi conduzido em um pomar comercial de banana "Maçã" localizado no município de Eunápolis, região sul do estado da Bahia. A área está localizada entre as coordenadas de Latitude 16²2'700"S e Longitude 39031'829"O e altitude média de 197 m.

O bananal possui três anos de idade com espaçamento de $3 \times 4 \mathrm{~m}$. 0 sistema de irrigação utilizado é por microaspersão e, em intervalos de 90 dias, é aplicado Trichoderma longibrachiatum, via fertirrigação, visando ao controle biológico do Fusarium oxysporum.

Antes da implantação do experimento, foram imersos cinco palitos de madeira de cada tratamento, em um litro do herbicida à base de glifosato, durante o período de uma hora. Após este período de imersão, esses palitos de madeira foram pesados para se estabelecer a dose fornecida para cada broto, conforme a tabela 1. O herbicida utilizado possui em sua composição 480 g. L-1 de sal de Isopropilamina de $\mathrm{N}$-(fosfonometil) glicina; 360 g. $\mathrm{L}^{-1}$ equivalente ácido de N-(fosfonometil) glicina (glifosato) e 684 g.L-1 de ingredientes inertes, na formulação concentrado solúvel.

Tabela 1: Peso seco e peso após a embebição do herbicida à base de glifosato aplicado em brotos de bananeira "Maçã" - Eunápolis-BA, 2014.

\begin{tabular}{lll}
\hline Material & Peso do material seco(g) & Peso após embebição(g) \\
\hline Palito de picolé & 1,47 & 1,88 \\
Palito de dente & 0,09 & 0,15 \\
Palito de churrasco & 1,57 & 1,78 \\
\hline
\end{tabular}

Fonte: Elaboração dos autores.

No dia 26 de dezembro de 2013, foi instalado o experimento com cinco tratamentos no delineamento experimental inteiramente casualizado, com quatro repetições, dispostos em parcelas subdivididas; a parcela era constituída de quatro plantas de banana "Maçã" que não apresentavam sintomas do Mal-do-panamá.

Os tratamentos testados correspondem a cinco formas de aplicação do glifosato nos brotos (vela) de cada planta da unidade experimental: T1- testemunha, T2 - palito de picolé, T3 - palito roliço de madeira para os dentes, T4 - palito roliço de madeira para churrasco feitos de bambu, T5 seringa; a subparcela eram as três épocas das avaliações (15, 30 e 60 dias após a aplicação).

Para a aplicação com a seringa, foram utilizadas agulhas descartáveis com $10 \mathrm{~cm}$ de comprimento, sendo uma para cada broto. A dose utilizada para aplicação com a seringa foi de $1,8 \mathrm{~mL}$ planta-1 $^{-1}$, dividida para os brotos e administrada apenas uma injeção por broto.

Para aplicação, foram escolhidas de dois a três brotos por planta, com altura máxima de 50 $\mathrm{cm}$. Foi inserido apenas um palito por broto, numa altura média de $20 \mathrm{~cm}$ acima do solo. Nessa mesma altura, foi introduzida a dose de glifosato no broto através da seringa.

A avaliação visual do efeito de toxicidade nos brotos foi realizada aos 15, 30 e 60 dias após a aplicação dos tratamentos. Foram atribuídas notas de um a nove, de acordo com o percentual de toxicidade nos brotos. Para tanto, utilizou-se a metodologia proposta por EWRC (1964) adaptada, segundo a qual, a nota um é atribuída aos brotos que não sofreram danos e nove, aos brotos que se encontravam mortos, conforme descrito na Tabela 2. Logo após a atribuição das notas, verificou-se visualmente se a toxicidade nos brotos foram translocadas para a planta mãe. 
Tabela 2: Escala visual de fitotoxicidade utilizada para avaliação do glifosato nos brotos de banana. EunápolisBA, 2014.

\begin{tabular}{ccc}
\hline Escala & Toxicidade (\%) & Característica da toxicidade \\
\hline 1 & 0 & Nenhuma toxicidade \\
2 & $1,0-3,5$ & Toxicidade muito leve \\
3 & $3,5-7,0$ & Toxicidade Leve \\
4 & $7,0-12,5$ & Toxicidade quase moderada \\
5 & $12,5-20,0$ & Toxicidade moderada \\
6 & $20,0-30,0$ & Toxicidade quase forte \\
7 & $30,0-50,0$ & Toxicidade forte \\
8 & $50,0-99,0$ & Toxicidade muito forte \\
9 & 100 & Morte das plantas \\
\hline
\end{tabular}

Fonte: European Weed Research Council (1964).

Foi realizado ainda o levantamento da incidência do Mal-do-panamá na propriedade. Para isso, fez-se uma amostragem aleatória com mil plantas, contabilizando aquelas que apresentavam o sintoma da doença, além das covas de onde as plantas severamente atacadas haviam sido arrancadas, e as que foram replantadas. 0 resultado foi expresso em porcentagem de ataque da doença na área.

Os dados relacionados à severidade foram submetidos à análise de variância. Os efeitos da interação entre os dias após a aplicação e as diferentes formas de desbaste foram estudados por meio do teste de Tukey a $5 \%$ de probabilidade.

\section{Resultado e discussão}

O desbaste químico por meio da injeção do herbicida pela seringa mostrou ser o mais eficiente em todas as épocas, verificando-se a morte dos brotos aos 15 dias após a aplicação do produto, sem ocorrência de fitotoxicidade do herbicida nas plantas mãe e planta filho não tratadas.

Pela análise de variância (Tabela 3), observou-se que houve efeito significativo da interação entre o desbaste químico e os dias após a aplicação a 1 \% de probabilidade.

Tabela 3: Resumo do quadro de análise de variância da fitoxicidade do glifosato aplicado em brotos de bananeira "maçã". Eunápolis - BA, 2014

\begin{tabular}{ccc}
\hline Fonte de variação & Graus de Liberdade & Quadrado médio \\
\hline Desbaste químico & 4 & $110,441^{* *}$ \\
Resíduo (A) & 12 & 0,78 \\
DAA & 2 & $10,55^{* *}$ \\
Desbaste químico x DAA & 8 & $3,77^{* *}$ \\
Resíduo (B) & 33 & 0,49 \\
\hline
\end{tabular}

*Significativo pelo teste "F" a $5 \%$ de probabilidade.; ** Significativo pelo teste "F" a $1 \%$ de probabilidade. DAA - Dias após a aplicação.

Fonte: Elaboração dos autores.

Os resultados sobre a eficácia dos tratamentos após 15, 30 e 60 dias de aplicação estão expressos na Tabela 4. 
Tabela 4: Fitotoxicidade de brotos de bananeira "Maçã" aos 15, 30 e 60 dias após a aplicação do glifosato por diferentes formas de desbaste químico. Eunápolis - BA, 2014

\begin{tabular}{llll}
\hline & 15 DAA & 30 DAA & 60 DAA \\
\hline Testemunha & $1,0 \mathrm{Ca}$ & $1,0 \mathrm{Da}$ & $1,0 \mathrm{Da}$ \\
Palito de Picolé & $5,75 \mathrm{Bb}$ & $7,5 \mathrm{Ba}$ & $5,5 \mathrm{Bb}$ \\
Palito de dente & $2,25 \mathrm{Cb}$ & $5,0 \mathrm{Ca}$ & $2,0 \mathrm{Db}$ \\
Palito de Churrasco & $6,75 \mathrm{Ba}$ & $6,0 \mathrm{Ca}$ & $3,75 \mathrm{Cb}$ \\
Seringa & $8,75 \mathrm{Aa}$ & $9,0 \mathrm{Aa}$ & $9,0 \mathrm{Aa}$ \\
\hline
\end{tabular}

\begin{tabular}{ll}
\hline C.V\% & CV\% na linha: 14,$21 ;$ CV\% na coluna: 17,91 \\
D.M.S & D.M.S na linha: 1,$22 ;$ D.M.S na coluna: 1,43
\end{tabular}

Médias seguidas de mesma letra, maiúscula na coluna e minúscula na linha, não diferem entre si pelo teste Tukey a $5 \%$ de probabilidade. DAA: Dias após a aplicação.

Fonte: Elaboração dos autores.

O desbaste químico por meio da injeção do herbicida pela seringa mostrou ser o mais eficiente em todas as épocas, verificando-se a morte dos brotos aos 15 dias após a aplicação do produto, sem ocorrência de fitotoxicidade do herbicida nas plantas mãe e filho não tratadas. Esses resultados corroboram os encontrados por Blomme et al. (2008) que relataram maior eficiência na morte de bananeiras ( Musa grupo ABB) quando injetado o herbicida à base de glifosato, com seringa, no pseudocaule, na concentração de 2,0 ml, sem afetar a planta mãe e os outros filhotes. De acordo com Blomme et al. (2008), o uso de injeções de herbicidas para destruir bananas mostra várias vantagens como o caráter sistêmico e a morte e decomposição das plantas, em um curto tempo. Além do mais, a eficiência do trabalho na aplicação é maior, visto que uma equipe de duas pessoas - com uma pessoa para fazer os furos no pseudocaule e a outra pessoa para injetar o herbicida - podem injetar até 215 pseudocaules por hora. Esse método aumenta significativamente o número de plantas destruídas em comparação com a remoção manual, utilizando facões e enxadas.

Estudos realizados por Martinez et al. (1988) relataram fitotoxicidade em plantas mãe e nos outros filhos não tratados com glifosato e picloran, quando aplicados em palitos de bambu impregnados com herbicida em doses elevadas. Segundo Cavalcante et al. (2005), no início de seu desenvolvimento, as plantas-filha dependem dos nutrientes supridos pela planta-mãe para se desenvolverem. Com seu crescimento, tendem a ficar independentes, mas enquanto formam um agrupamento de plantas interligadas, mães e filhas podem manter alguma interdependência, trocando nutrientes.

Para os tratamentos por intrusão mecânica de herbicidas com os palito de picolé e palito de churrasco, observou-se que, aos 15 dias, o herbicida aplicado por essas formas proporcionam injúrias, de moderadas a quase forte. Aos 30 dias, os tratamentos por meio de palitos de picolé e de dente demonstraram um aumento na fitotoxicidade, no entanto, com o passar do tempo, a diferença de fitotoxicidade entre os três tratamentos com palitos ficou menor, tendendo a não mais apresentar sintoma de toxicidade (TABELA 4). Isso provavelmente ocorreu porque a concentração do produto nos palitos não é suficiente para levar à morte da planta. Além disso, a tolerância de culturas a herbicidas depende de uma série de fatores, entre eles o estádio de crescimento das plantas. Dessa forma, aos 60 dias após a aplicação, certamente as plantas que foram tratadas por meio dos palitos de madeira já estavam mais tolerantes à ação do herbicida (OLIVEIRA, 2013). Martinez et al. (1988) constataram que o desbaste de brotos de bananeira com palitos de madeira de bambu impregnados com herbicidas foi cem por cento efetivo e que o tempo de absorção de herbicidas pelos palitos de bambu poderia ser menor que um minuto. 
Quanto à área da propriedade, verificou-se uma baixa incidência do Mal-do-panamá, com apenas 9,8 \% da área com sintomas visíveis. Isso ocorre provavelmente em razão do manejo realizado com a aplicação trimestral do Trichoderma longibrachiatum, da conservação de maior número de brotos nas touceiras, evitando a proliferação do fungo pelo uso de ferramentas para desbaste, além da interação de outros prováveis fatores, a exemplo de controle de plantas daninhas e da adubação adequada.

A utilização do controle biológico constitui uma estratégia para o controle de patógenos de solo, que atuam a partir da produção de metabólitos antimicrobianos secundários (antibiose), enzimas líticas, entre outros. Nesse sentido, o gênero Trichoderma é um dos mais utilizados, representando fungos não patogênicos que exercem antagonismo a vários fitopatógenos por intermédio do parasitismo e/ou antibiose (MILANESI et al., 2013). Assim, a competição entre Trichoderma e Fusarium pode ser o mecanismo chave para o biocontrole desse patógeno em solos (KIM e KNUDSEN, 2013).

\title{
Conclusão
}

O desbaste químico de brotos de bananeira "Maçã" com o uso do glifosato injetados por seringa é mais eficiente que os métodos de intrusão por palitos de picolé, palitos de dente e palitos churrasco.

$\mathrm{O}$ desbaste químico com o uso da seringa é cem por cento efetivo, levando à morte de todos os brotos de bananeira tratados com o glifosato, o que pode ser uma alternativa viável para o desbaste, reduzindo assim a transmissão do Fusarium oxysporum.

\section{Agradecimentos}

À CAPES, pela concessão da bolsa.

\section{"Apple" banana tree chemical thinning of shoots for Fusarium oxysporum control}

\begin{abstract}
The "Apple" banana has a high susceptibility to Fusarium. Therefore, the present study aims to evaluate different forms of chemical thinning with glyphosate in shoots of "Apple" banana tree, in order to reduce the transmission of Fusarium oxyporum, agent that causes Panama disease. The experiment was conducted with five treatments in a completely randomized design, in which, each plot consisted of four plants of "Apple" banana. The treatments refer to five ways to apply glyphosate in shoots (bougie) of each plant: T1-attestant , T2 - popsicle stick T3- toothpick for teeth T4- toothpick for BBQ , T5 - syringe. The visual assessment of the effect of toxicity in shoots was performed at 15 , 30 and 60 days after treatment application. We graded from one to nine according to the severity of the damage in shoots. The chemical thinning by injecting herbicide with a syringe was the most efficient way to apply at all times, leading to death of $100 \%$ of the shoots after 15 days after applying the product which can be an excellent alternative to thinning, thus reducing the transmission of Fusarium oxysporum.
\end{abstract}

Keywords: Panama disease. Glyphosate. Musa spp. 


\section{Referências}

ANDRADE, G. J. M.; ROSOLEM, C. A. Absorção de manganês em soja RR sob efeito do glifosate. Revista Brasileira de Ciências do Solo, v.35, n.3, p.961-968, 2011.

BLOMME, G.; TURYAGYENDA, L. F.; MUKASSA, H.; EDEN-GREEN, S. The effectiveness of different herbicides in the destruction of banana Xanthomonas wilt infected plants. African Crop Science Journal, v.16, n.1, p.103-110, 2008.

BORGES, A. J. S. TRINDADE, A. V.; MATOS, A. P.; PEIXOTO, M. F. Redução do mal-do-Panamá em bananeira maçã por inoculação de fungo micorrízico arbuscular. Pesquisa Agropecuária Brasileira, v.42, n.1, p.35-41, 2007.

BRASIL. Ministério da Saúde. Agência Nacional de Vigilância Sanitária. Sistemas de Informação sobre Agrotóxicos. Disponível em: http://www.anvisa.gov.br// Acesso em: 27 mar. 2014.

CAVALCANTE, A. T.; SAMPAIO, E. V. de S. B.; CAVALCANTE, U. M. T. Interdependência na absorção e redistribuição de fósforo entre planta mãe e filha de bananeira. Revista Brasileira de Fruticultura, v.27, n.2, p.255-259, 2005.

CORDEIRO, Z. J. M.; KIMATI, H. Doenças da bananeira (Musa sp.). In: KIMATI, H.; AMORIM, L.; BERGAMIN FILHO, A.; CAMARGO, L. E. A.; REZENDE, J. A. M. (Eds.). Manual de fitopatologia: doenças das plantas cultivadas. 3.ed. São Paulo: Agronômica Ceres. v.2, p.112-136. 1997.

COX, C. Glyphosate factsheet. Journal of Pesticide Reform, v.108, n.3, 1998, rev. 2000.

EMBRAPA.Empresa Brasileira de Pesquisa Agropecuária. Disponível em: http://sistemasdeproducao. cnptia.embrapa.br/FontesHTML/Banana/Bananeiralrrigada/tratos.htm\#desbaste. Acesso em: 17 mar. 2014.

EWRC. Report of 3rd and 4rd meetings of EWRC. Cittee of methods in weed research. Weed Research, v.4, n.1, p.88. 1964.

FAO. Food and Agricultural Organization. Disponível em: http:// apps.fao.org/page/ collections. Acesso em: 24 de fevereiro de 2014.

FERREIRA, D. F. SISVAR - Sistema de análise de variância. Versão 5.3. Lavras-MG: UFLA, 2010.

IBGE. Instituto Brasileiro de Geografia e Estatística. Disponível em: http://www.sidra.ibge.gov.br/ bda/agric/default.asp. Acesso em: 24 fev. 2014.

JEROME, K.; JAMES, M.; VIGHERI, V. V.; JOHNSON, K. J.; ROCKEFELLER E.; IVAN, R.; WILBERFORCE, T.; FINA, O. Strategies for rehabilitation of banana fields infested with Xanthomonas campestris pv. musacrearum. Journal of Crop Protection. v.3, n.1, p.21-29. 2014.

LINDSAY, S.; PATTISON, T.; MURAD, Z. Eradicating banana crops with herbicide injection for better IPM and environmental outcomes. Agency for Food and Fibre Sciences, Horticulture. September 2003, Issue 33. Disponível em: http://www.dpi.qld.gov.au/bananatopics/12423.html. Acesso em: 19 out. 2014. 
KIM, T.G.; KNUDSEN, G.R. Relationship between the biocontrol fungus Trichoderma harzianum and the phytopathogenic fungus Fusarium solani f.sp.pisi. Applied Soil Ecology, v. 68, n.68, p.57-60. 2013.

LEONEL, S.; DAMATTO JUNIOR, E. R. Caracterização das áreas de cultivo da bananeira 'maçã' na região de Ribeirão do Sul-SP. Ciência e Agrotecnologia, v.31, n.4, p.958-965. 2007.

MARTINEZ, J. A.; YAMASHIRO, T.; OLIVEIRA, D.A. Desbaste da bananeira por meio de palitos de madeira impregnados com herbicida. In: CONGRESSO BRASILEIRO DE FRUTICULTURA, Anais... Campinas. Sociedade Brasileira de Fruticultura, Campinas. p. 155-160. 1988.

MILANESI, P. M.; BLUME, E.; MUNIZ, M. F. B.; REINIGER, L. R. S.; ANTONIOLLI, Z. I.; JUNGES, E.; LUPATINI, M. Detecção de Fusarium spp. e Trichoderma spp. e antagonismo de Trichoderma sp. em soja sob plantio direto. Semina: Ciências Agrárias, v.34, n.6, suplemento 1, p.3219-3234. 2013.

OKURUT, A. W.; TUSHEMEREIRWE, W. K.; ARITUA, V.; RAGAMA, P. E. Use of herbicides for control of banana bacterial wilt in Uganda. African Crop Science Journal, v.14, n.2, p.143-149. 2006.

OLIVEIRA, M. B. de O.; ALVES, P. F. S.; TEIXEIRA, M. F. F.; SILVA, H. D.; SÁ, R. A.; CAMPOS, R. G. C.; CARVALHO, A. J. de; ASPIAZÚ, I. Fitotoxicidade de herbicidas aplicados em diferentes épocas em pós-emergência do feijão-caupi. Revista Unimontes Científica, v.15, n.1, p. 64-70. jan. 2013.

PLOETZ, R. C. Fusarium Wilt of Banana Is Caused by Several Pathogens Referred to as Fusarium oxysporum f. sp. cubense. Phytopathology. v.96, p.653-656. 2006.

STOVER, R. H.; WAITE, B. H. Inoculation studies and natural infection of banana varieties with races 1 and 2 of Fusarium oxysporum f. sp. cubense. Canadian Journal of Botany. v.38, n. 1, p. 985-994. 1960.

\section{Histórico editorial}

Submetido em: 27/05/2014

Aceito em: 30/10/2014 